\title{
TRENDING HYBRID SURGERY FOR ANAL FISTULAE [FILAC + SLOFT] TO CURTAIL RECURRENCE SUCCEEDING IN 24 CASES
}

\section{General Surgery}

Neeti Neha*

\section{Gaurikant Mishra}

MBBS, MS General Surgery, FIAGES ,Assistant Professor, General Surgery Dept., JNKTMCH, Madhepura, Bihar, India. *Corresponding Author

MBBS; MS General Surgery; Professor and Principal; JNKTMCH; Madhepura; Bihar, India

\section{ABSTRACT}

Objective: The aim of the study is to evaluate the efficacy of upcoming operative combination of fistula laser tract closure [FiLaC] + submucosal ligation of fistula tract [SLOFT] in treating anal fistulae. Background: The treatment of anal fistulae is predominantly surgical. To attain a minimum recurrence healing, the surgical methods have gone through a chain of transitions. One of the fresh developments has been a hybrid of FiLaC and SLOFT, sometimes described as distal laser proximal SLOFT [DLPS] procedure. Materials and methods: The study was winded up on a total of 24 patients since September 2019 to August 2020. All, regardless of type of fistula, underwent an operative blend of FiLaC and SLOFT, after explaining the pros and cons of the bouquet of surgical options available. Results: The results of FiLaC and LIFT [Ligation of intersphincteric fistulous tract] have been individually questioned over past years. SLOFT is a recent modification inculcating the benefits of LIFT and at the same time, snagging for the cryptoglandular complex with minimal dissection. Conclusion: Our study on 24 cases has strengthened the togetherness of FiLaC and SLOFT in treating anal fistulae.

\section{KEYWORDS}

Anal fistula, FiLaC, hybrid, recurrence, SLOFT

\section{INTRODUCTION:}

Anal fistulae, as goes for any fistula, is a tunnelled communication between two epithelial lined surfaces; and the lining bricks made by infected granulation tissue and inflammatory cells. Etiologically, almost all anal fistulae (95\%) are thought to originate from infected cryptoglandular complex. As a result of bodily defence to contain the infection, abscess forms and if not drained internally, tracks down over perianal skin creating a fistula. Long standing cases tend to offshoot some secondary tracts too. Depending upon whether the tracts disturb the levator- pubrectalis sling or traverse more than $30 \%$ sphincter, fistulae in women, anterior fistulae, recurrent or those associated with inflammatory bowel disease or radiation, they are termed complex or high and those which are low enough are called simple anal fistulae. Besides seeding through the anal glands, a minor bulk (5\%) of anal fistulae are a result of neoplasm, radiation, trauma or an illustration of some chronic granulomatous diseases, namely crohn's disease, ulcerative colitis, tuberculosis and others. Current percentage distribution of Dr Park's classification of anal fistulae areIntersphincteric- $70 \%$

Transsphincteric- $25 \%$

Suprasphincteric- $5 \%$

Extrasphincteric- $1 \%$

The last two are often the sequelae of ischiorectal abscesses. Initial evaluation includes clinically inspecting and palpating for openings and tracts. Sticking to the basics of Goodsall's law, internal opening is often appreciated as a dimple or induration at its location. A coronal plane is assumed passing through midline of the anus. The anal orifice is viewed as a clock and the o'clocks refer to the hands of a clock, when we look at it sitting between the parted legs of the patient in lithotomy position, the $120^{\prime}$ clock being the topmost midline, correspond- ing to penis in men and vaginal orifice in women. The rule suggests if external orifice lies anterior to this line, the tract courses radially and follows a straight path having internal origin at the same position. If the external orifice lies posterior to the plane, all converge to originate at $6 o^{\prime}$ clock position. While if the external opening lies at a distance more than around $3 \mathrm{~cm}$ from the anal verge either anterior or posterior, they have a curvilinear trajectory incepting internally at $60^{\prime}$ clock position. All internal orifices originating from cryptoglandular complex have to be present at the level of dentate line indefinitely. However, fistulae secondary to radiation or some granulomatous disorders as Crohn's, may not likely comply with the rule. Further, DRE and anoscopy also help in excluding increased anal tone and co-existing haemorrhoids, if any. Radiological diagnostics range from fistulography, endoanal ultrasound, computed tomography $(\mathrm{CT})$ and magnetic resonance imaging(MRI). Fistulography used to refer to X-Ray images after injecting contrast in the external opening of the fistula and is considered obsolete. Endoanal ultrasound has its limitations in long trajectory fistulae, due to restricted penetration. Considering the soft tissue involvement and relations to the sphincteric complex, MRI with
T1, T2 and contrast sequences is the gold standard investigation till date. $[1,2,3,4]$ Saint James University Hospital studied the landmarks on the axial plane and evolved another grading system:

Grade I- simple linear intersphincteric

Grade II- intersphincteric with abscess or secondary tract Grade III- transsphincteric

Grade IV- transsphincteric with abscess or secondary tract within the ischiorectal fossa

Grade V-supralevator and translevator extension.

Treatment is primarily some sort of surgical intervention and has been broadly grouped as sphincter cutting or sphincter sparing. Sphincter cutting procedures include fistulotomy and fistulectomy. Fistulotomy or laying open of the entire tract and marsupialisation, has its present day usage in low lying fistulae due to the risk of damaging sphincteric complex. Fistulectomy refers to excising the entire tract and repairing the incised sphincter complex and anoderm. An urge towards acceptance of minimally invasive procedures in all surgical domains created a quest towards sphincter sparing procedures in proctology too. The justification came as when given a choice, patients are willing to accept recurrence rather than incontinence. Many were suggested such as

- LIFT

- FiLaC

- VAAFT

- Fixcision

- Application of flaps, plugs, glue

- Advancement flaps

None of the above has been proved full proof to recurrence, unfortunately. So, a continuous struggle remains in minimising the incidence of relapse without threatening the sphincter function. LIFT was amongst the first in the reign of minimally invasive proctology. We, at our centre, were practising the FiLaC procedure with $1470 \mathrm{~nm}$ $15 \mathrm{~W}$ diode laser (Lasotronix smart $\mathrm{t}^{\mathrm{m}}$ ), until recently, when we decided to add upon SLOFT to the technique, considering a better dealing of the anal glands infection. This meant dissecting out the intersphincteric plane to reach the cryptoglandular complex and dismantling the proximal and distal portions of the fistulous tract. SLOFT was a wise modification by gaining access to the same through a mucosal incision around $5 \mathrm{~mm}-1 \mathrm{~cm}$ caudal to the internal opening. [5,6,7]

Aims and objectives: The aim of the study is to emphasise the role of FiLaC plus SLOFT in treating anal fistulae by elaborating upon the steps and validating their usage in more number of patients in future. Limitation: Before generalising the treatment to all anal fistulae, the authors accept the limiting numbers of patients and the duration of follow up in our study. Moreover, our study more aptly fits the frame of 
case control study rather a randomised control trial or a comparative analysis.

\section{Patients and methods:}

We carried out this combination of FiLaC and SLOFT in 24 patients over a span of 1 year [September 2019-August 2020]. All patients underwent a detailed clinical history, digital rectal examination and were explained the treatment options available. Associated ailments were seeked and piles, fissure or both were included. An informed consent of the operative procedure was taken from each individual, which also included justified surgery for other anal symptoms as well, in the same sitting. Baseline laboratory tests and MRI were carried out on all and a preanaesthetic and OT consent approval taken. An average wait time of 2 weeks with antibiotic coverage was taken in all anal fistulae associated with abscesses. All patients were under spinal anaesthesia and in lithotomy position. Hydrogen peroxide solution followed by methylene blue were injected through external opening to correlate with the MRI finding of internal opening. A fistula probe was negotiated through external to internal opening and an infant feeding tube[IFT] of $9 \mathrm{Fr}$ was rail roaded over the probe. The radial laser fibre was inserted now through the IFT. A mucosal incision around $1 \mathrm{~cm}$ distal to internal opening was given to reach the tract. Two figure of eight stitches with vicryl 2-0, polyglactin 910 were secured for proximal portion of fistula, ensuring that proximal fistula tract has been circumscribed in the bites taken.[Figure1-A] Those in whom the internal opening couldn't be appreciated, following the Goodsall's rule, the presumptive location according to the same rule, is closed with the suture. Laser fiber is then advanced a bit distal to the IFT, so that the glass tip projects beyond. Around $100-150 \mathrm{~J}$ of energy were fired the cryptoglandular complex, cautiously not burning the sutures. In case the suture disrupts, this has to be re-done. The fiber was then gradually pulled back, pulling the sutures ends with the other hand and a give way click is appreciated. Now, the sutures are tied, and the distal portion of tract was dismantled with scissors.[Figure1-B] The surgeon can otherwise make use of bare laser fibre or electrocautery to do the same. The laser fibre with IFT is then gradually pulled with firing of $100 \mathrm{~J}$ per $\mathrm{cm}$ or at $10 \mathrm{~W}, 3$ seconds every $5 \mathrm{~mm}$ continuous mode setting. We prefer to close the mucosal incision given at the beginning of surgery as well, but it has been described to keep it open so as to flush the burnt tract in postoperative dressings. The external opening is enlarged give a broader vent to the created debris and left open for secondary healing.[Figure 1-C] An external part of fistulous tract was always sent for histopathological examination and RT-PCR for mycobacterium tuberculosis analysis.[Figure1-D] Other ailments such as piles or internal sphincter hypertrophy were treated at this step.[Figure1-E] Rectal and wound packings done. All patients were discharged after removing the packs post 12 hours and ruling out any active bleed. Post operative care included sitz baths, oxum spray application over perianal wound and diaper usage in all for 1 week. Follow up intervals were at third, seventh postoperative days and at 1 and 6 months.

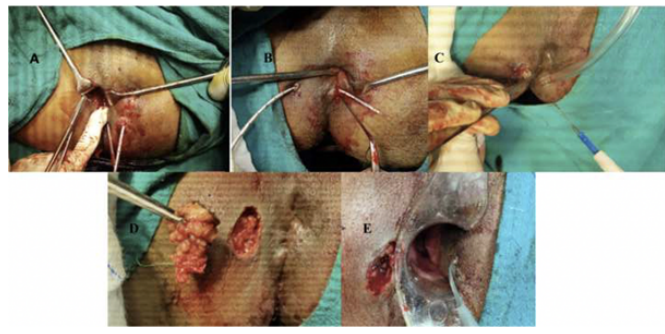

Figure 1 :Figure showing steps $[\mathrm{A}-\mathrm{E}]$ of FiLaC + SLOFT in different patients.

\section{RESULTS:}

Statistical data were summarised using percentages and means, and comparative data with other studies were calculated using chi square test of independence.

\section{Chi square $=$ summation $\lfloor$ eij - oij $\rfloor 2$}

\section{eij}

where eij is the expected cell count and oij is the observed cell count in the ith row and jth column of the contingency table under comparison.

Formula for eij $=\underline{\text { row i total } * \text { column j total }}$ grandtotal

Probability[p- value] was computed after comparing to the critical value from chi square distribution table with degrees of

freedom $=($ number of rows- 1$)$ (number of columns- 1$)$ and selecting a confidence level. If the calculated value $>$ critical value from the table, then the probability becomes significant and we reject the null hypothesis, strengthening the validity of the present study. [Table1, Table2, Figure2].
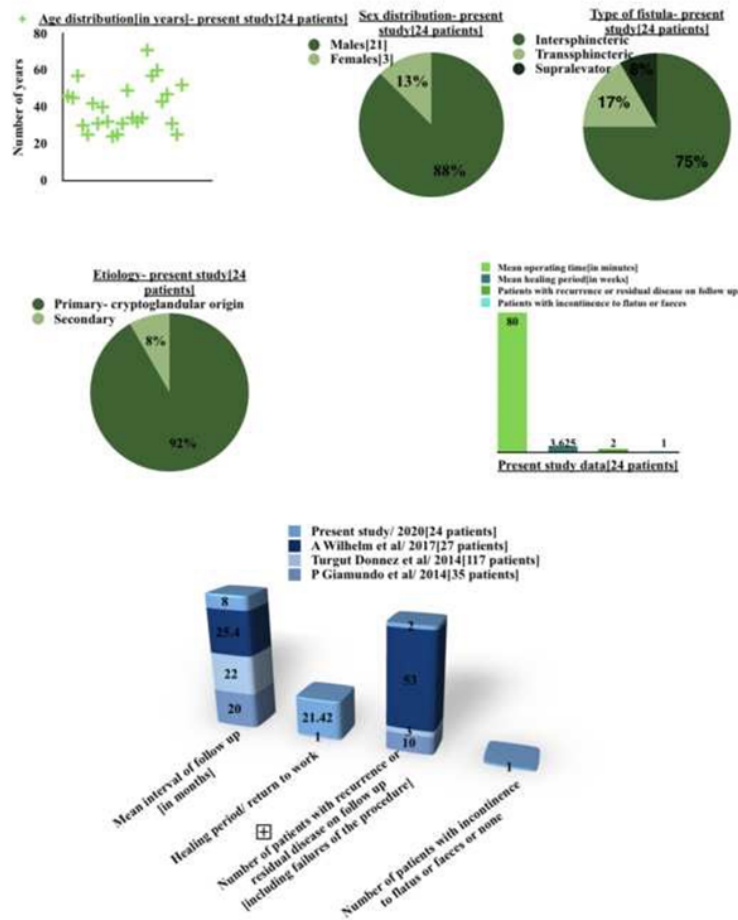

Figure 2: Bar charts and pie charts showing the results of the present study as well as comparing with other 3 studies.

Table 1: Master chart summarising the data of present study.

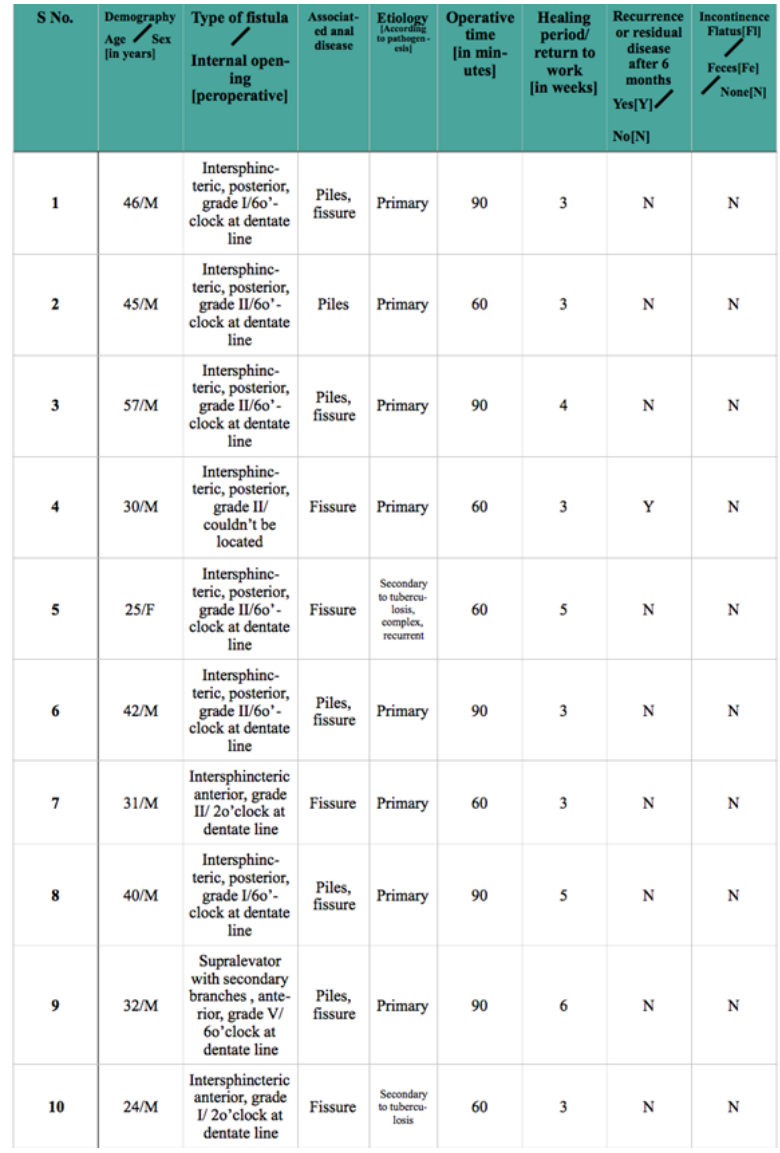




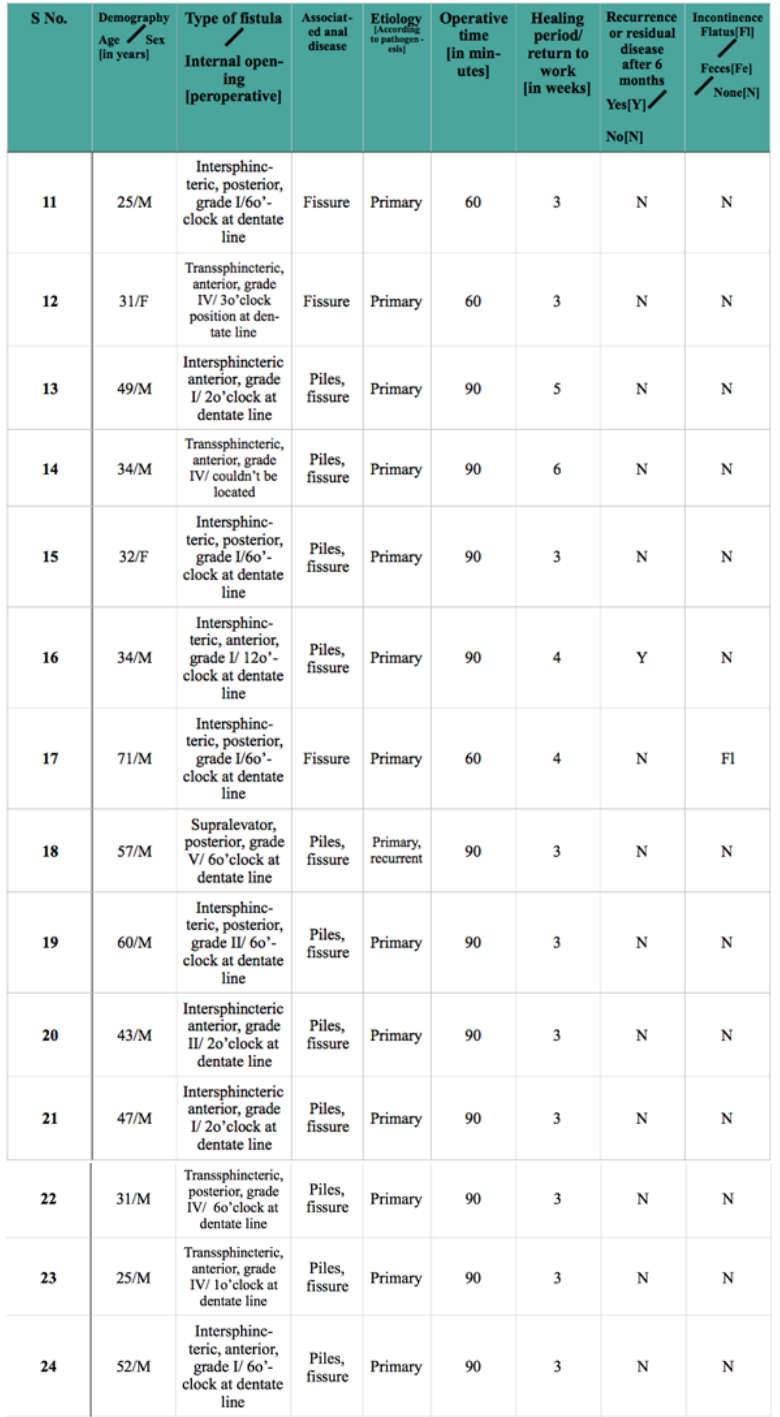

Table 2: Comparison table between 4 studies, including the present one.

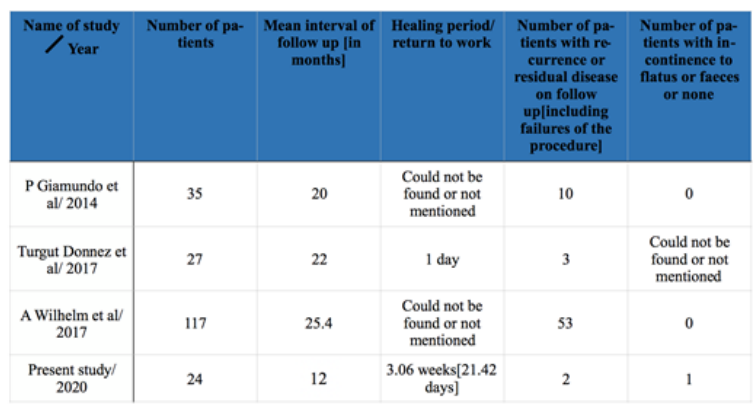

- $p$ - value $>0.05$ : when present study[FiLaC + LIFT overall compared with $P$ Giamundo et al 2014 study[FiLaC] : insignificant at $95 \%$ confidence interval.

- $\mathrm{p}$ - value $<0.01$ : when present study[FiLaC + LIFT] overall compared with Turgut Donnez et al 2014 study[FiLaC] : significant at $99 \%$ confidence interval.

... $p$ - value $<0.01$ : when present study[FiLaC + LIFT] overall compared with A Wilhelm et al/2017 study[FiLaC] : significant at $99 \%$ confidence interval.

DISCUSSION:

Demographic plotting revealed the mean age of patients as 40.13 years. Of all, $88 \%$ were men and $13 \%$ were women. The type of fistula distribution as found in this study is intersphincteric- $75 \%$; transsphincteric- $17 \%$ and supralevator- $8 \%$. This closely relates to the percentages of the Cochrane study. We deduced $92 \%$ anal fistula to be primary, that is a result of infected cryptoglandular complex. Only 2 patients were found to have anal fistula and a history of extrapulmonary tuberculosis as well. Mean operating time was calculated to be 80 minutes, while mean healing period was 3.625 weeks. 2 patients continued to have purulent discharge per rectally on/off after a mean follow up period of 8 months, and 1 patient complained of involuntary passage of flatus. We searched over the research literature on FiLaC. Since its common familiarity since 2011, we found three major studies heralded by P Giamundo et al in 2014, Turgut Donnez et al in 2017 and A Wilhelm et al in 2017. We collated the four studies, with comparing parameters as mean interval of follow up [in months], healing period/ return to work, number of patients with recurrence or residual disease on follow up[including failures of the procedure] and number of patients with incontinence to flatus or faeces. Our data with FiLaC + SLOFT technique was found superior overall to the latter two studies, with p-value significant at $95 \%$ confidence interval. The study was however, failed to prove so with the former study of P Giamundo et al. $[8,9,10]$

\section{CONCLUSION:}

There is a growing interest in minimally invasive techniques evading all surgical fields. LIFT [Ligation of intersphincteric fistula tract] and FiLaC[Fistula laser tract closure] were being singly tried for years in the cure of anal fistulae, struggling to establish their feet in the surgical theatres. FiLaC plus SLOFT [Submucosal ligation of fistulous tract] has come up as a novel surgical hybrid in the management of anal fistulae. Long term follow ups are however necessitated to unify this even more firmly.

\section{Acknowledgement:}

We feel indebted to the radiologist, anaesthetist, operating theatre staffs and the patients for all the support bestowed.

Ethical approval: not required.

Conflict of interests: none.

Abbreviations:

DLPS-Distal laser proximal SLOFT

FiLaC-Fistula laser tract closure

IFT- Infant feeding tube

LIFT- Ligation of intersphincteric fistula tract SLOFT- Submucosal ligation of fistulous tract VAAFT- Video assisted anal fistula treatment

\section{REFERENCES:}

1. ParksAG,GordanPH,HardcatleJd, A classification of Fistula in ANO .Br.J Surg. 1976:63:1 doi:10.1002|bjs.18006301029(PUB MED)(Cross Ref)(Google Scholar).

Limura E, Giordano P modern management of anal fistula world J gastroenterol 2015 , 21:12:20.

3. Gordon PH, Nivatvong S, Mulholland MWRef Principles \& Practice of surgery for the colon rectum \& anus. Shock 1999; 12:328.

4. Kamal Gupta et al(2019) 'Distal Laser Proximal SLOFT(DLPS)- A New Approach fo Management of Fistula in Ano', International Journal of Current Advanced Research,08(07), pp-19374- 19377.

5. Parks AG. Pathogenesis and treatment of fistula-in-ano. Br Med J 1961;1(5224):463-9. Halligan S, Buchanan G. MR imaging of fistula-in-ano. Eur J Radiol 2003; 47(2):98-107. Han JG, Wang ZJ, Zheng Y, et al. Ligation of Intersphincteric Fistula Tract vs Ligation of the intersphincteric Fistula Tract plus a bioprosthetic anal fistula plug procedure in patienth patients with transsphincteric anal fistula: early results of a multicenter prospective 000000001562. [PubMed] [CrossRef] [Google Scholar].

8. Giamundo P, Geraci M, Tibaldi L, Valente M. Closure of fistula-in-ano with laser-FiLaCTM: an effective novel sphincter-saving procedure for complex disease. Colorectal Dis. 2014;16(2):110-115.

9. Turgut Dönmez, Engin Hatipoğlu. Closure of Fistula Tract With FilacTM Laser As Sphincter Preserving Method in Anal Fistula Treatment. Turk J Colorectal Dis. Dec 2017; pages 1-6.

10. AWilhelm, AFiebig, MKrawczak. Five years of experience with the FiLaCTM laser for fistula-in- ano management: long-term follow-up from a single institution. Tech Coloproctol. 2017;21(4): 269-276. 